\title{
Factors affecting peak expiratory flow variability and bronchial reactivity in a random population
} sample

Bernard G Higgins, John R Britton, Susan Chinn, Kam Kwong Lai, Peter G J Burney, Anne E Tattersfield

\begin{abstract}
Background-Bronchial reactivity measurements are widely used in epidemiological studies to provide an objective marker of asthma. There are, however, several potential advantages of measuring peak expiratory flow (PEF) variability instead, particularly in large studies. PEF variability and bronchial reactivity were compared in a population sample to assess the relationships of the two measurements to factors known to be associated with airways disease, and to compare their response rates.

Methods-Subjects aged 18-65 were randomly selected from the electoral register of an administrative area in eastern England and randomised to attend either for a bronchial challenge test measuring the provocative dose of methacholine producing a $20 \%$ fall in $\mathrm{FEV}_{1}\left(\mathrm{PD}_{20}\right)$, or to measure PEF at two hourly intervals during waking hours for one week. Skin tests with common allergens were performed and a smoking history obtained. PEF variability was expressed as the amplitude \% mean (highest - lowest $\times$ $100 /$ mean).
\end{abstract}

Results-A total of 273 subjects (69\%) collected a PEF meter but a completed record sheet was returned by only 247 $(62 \%)$; this was still significantly more than the 202 subjects (54\%) who attended for and successfully completed a challenge test. Amplitude \% mean was higher in women than in men $(9.7 \% v 8.5 \%)$. In multiple regression analysis amplitude \% mean increased significantly with age, mean skin weal diameter, and with current smoking. The odds of having a $\mathbf{P D}_{20}$ below $24.5 \mu \mathrm{mol}$ increased with mean skin weal diameter and were greater in current smokers. Neither age nor sex had a significant effect on bronchial reacitvity but there were significant interactions between age and the effects of both smoking and atopy.

Conclusions-The higher response rate associated with the use of PEF variability measurement, and the association with factors implicated in the pathogenesis of airways disease, suggest that PEF variability would be a useful measurement to employ in epidemiological studies.

(Thorax 1993;48:899-905)
The inclusion of an objective measurement of bronchial reactivity in epidemiological investigations of asthma overcomes some of the problems of identifying asthma in the community and enables comparisons to be made between studies performed in different countries. It has become clear, however, that bronchial reactivity does not have as precise a relationship to the clinical diagnosis of asthma as was originally thought. ${ }^{1-5}$ There are, in addition, several practical problems associated with the measurement of bronchial reactivity in the community, including the invasive nature of challenge tests, the necessity of having a doctor present during the test, and the difficulties of obtaining a conventional measurement of reactivity such as the provocative dose of methacholine producing a $20 \%$ fall in $\mathrm{FEV}_{1}\left(\mathrm{PD}_{20}\right)$ in most subjects in a random population sample when dosage of bronchoconstrictor agents is limited by side effects.

We have explored the use of serial peak expiratory flow (PEF) recordings to try to circumvent some of these problems. In addition to the practical benefits, this method has the advantage of measuring directly the diurnal variability of airway calibre which is a cardinal feature of asthma. We have shown that collection of PEF recordings from previously untrained subjects is feasible, and that the data can be analysed to provide a numerical index of PEF variability which shows the expected relationship to the diagnosis of asthma. ${ }^{6}$ Although these findings suggest that the use of PEF variability might be an alternative to measurement of bronchial reactivity for community surveys of asthma prevalence, there are several unanswered questions. Our earlier study was performed in a small random sample together with a group of subjects selected because of respiratory symptoms, and did not permit an adequate consideration of the association of PEF variability with such factors as atopy and smoking. These associations are important since the value of PEF variability as an epidemiological tool would be questionable if it showed no relationship to factors implicated in the development and clinical diagnosis of airways disease. Furthermore, the possibility that measurement of PEF variability would be more acceptable to subjects in a community setting, and thereby achieve higher response rates, has not been explored.

We have therefore measured PEF 
variability and bronchial reactivity in a random sample of the population aged 18-65 from a semirural area in eastern England. Our aims were to compare the response rates of the two methods in conditions which imposed the kind of logistic difficulties that would be encountered in a major epidemiological study, to define the relationship between PEF variability and atopy and smoking in a random population sample, and to compare this with the relationship between bronchial reactivity and the same factors.

\section{Methods}

\section{SUBJECTS}

The study was conducted in South Kesteven, an electoral district in Lincolnshire covering an area of 364 square miles. The population of 99653 (established 1984) is divided between three towns and numerous villages. A random start systematic sample of 1100 names was drawn from the electoral register of the area and randomised into two groups, one to undergo bronchial challenge testing with methacholine and the other to keep a record of serial PEF measurements.

Subjects were sent a letter explaining the purpose of the study and asking them to keep an appointment for a challenge test or to collect a peak flow meter. A prepaid envelope and a reply slip were enclosed with the initial letter and the subjects were asked to inform us whether or not they would participate. The letter explained that we only wished to test those aged 65 or under, and older subjects were asked to indicate on the reply slip if they would not attend for reasons of age. A second letter containing the same information was sent to all non-responders three weeks after the first approach. Tests were conducted at several health centres throughout the area to reduce the travel required and, if necessary, subjects were visited at home. Attempts were made to contact all subjects who did not reply to either letter by visiting their address and, if possible, the test was rearranged at this time.

Approval for the study was obtained from the ethics committees of Nottingham City Hospital, South Lincolnshire Health Authority, and the South Lincolnshire General Practitioner Committee.

QUESTIONNAIRE

Information on respiratory symptoms, smoking history, age, and sex was obtained from all subjects using the bronchial symptoms

Table 1 Response in the sample drawn from electoral register

\begin{tabular}{lrc}
\hline & Challenge test group & PEF group \\
\hline Ineligible & 170 & 158 \\
Refused & 145 & 103 \\
Moved within area: & 9 & 6 \\
not traced & 11 & \\
Not accounted for & 212 & 12 \\
Attended for test & 547 & 552 \\
Total & & \\
\hline
\end{tabular}

Table 2 Distribution of sex, age, atopy, and smoking history among the subjects with complete data for all parameters

\begin{tabular}{|c|c|c|}
\hline & Challenge test group & PEF group \\
\hline \multicolumn{3}{|l|}{ Sex } \\
\hline Men & $85(50 \%)$ & $104(48 \%)$ \\
\hline Women & $86(50 \%)$ & $114(52 \%)$ \\
\hline Age median (range) & $39(18-64)$ & $41(18-64)$ \\
\hline \multicolumn{3}{|l|}{ Atopy } \\
\hline Atopic ${ }^{\star}$ & $60(35 \%)$ & $80(37 \%)$ \\
\hline Non-atopic ${ }^{\star}$ & $111(65 \%)$ & $138(63 \%)$ \\
\hline \multicolumn{3}{|l|}{ Smoking } \\
\hline Non-smoker & $75(44 \%)$ & $107(49 \%)$ \\
\hline Ex-smoker & $33(19 \%)$ & $42(19 \%)$ \\
\hline Current smoker & $63(37 \%)$ & $69(32 \%)$ \\
\hline
\end{tabular}

*Atopic-any skin weal $\geqslant 2 \mathrm{~mm}$ greater than saline weal; $\vec{O}$ non-atopic-no skin weal $\geqslant 2 \mathrm{~mm}$ greater than saline weal.

questionnaire of the International Union $\stackrel{x}{\infty}$ Against Tuberculosis (IUAT). This was com- 0 pleted before performing bronchial challenge tests or starting peak flow recordings.

BRONCHIAL CHALLENGE TESTS

The initial letter to the subjects included $a \mathbb{\infty}$ request to abstain from cigarettes and bron- $\frac{\vec{D}}{\vec{D}}$ chodilators for six hours before attending the $\frac{3}{0}$ test centre. On arrival the subjects rested $\stackrel{\mathbb{Q}}{-}$ while informed consent was obtained, the $\vec{\theta}$ questionnaire completed, and skin tests performed. Recordings of forced expiratory volume in one second $\left(\mathrm{FEV}_{1}\right)$ and forced vital capacity (FVC) were then made with a dry bellows spirometer (Vitalograph, 을 Buckingham, UK) until two successive FEV 1 ฉ measurements were within $5 \%$ of each other, $\overrightarrow{\vec{O}}$ the highest of these being taken as the base- 3 line reading. Subjects were excluded from challenge testing if their baseline $\mathrm{FEV}_{1}$ was less than $60 \%$ predicted, if the $\mathrm{FEV}_{1} / \mathrm{FVC}$ ratio was less than $50 \%$, if they had recently experienced a serious illness, or if they were pregnant.

Bronchial challenge tests were performed by the method of Yan et $a l$ using metha- $₹$ choline inhaled from De Vilbiss No 40 nebu-으 lisers which had all been shown by prior $D$ testing to have an output in the range $0.0025-0.0035 \mathrm{ml}$ per activation. After completing baseline spirometry subjects inhaled normal saline followed by increasing concen- $N$ trations of methacholine with measurement $\mathrm{N}$ of $\mathrm{FEV}_{1}$ one minute after each dose, always recording the highest of two readings withine $5 \%$ of each other. Quadrupling increments of methacholine from a starting dose of $0.096^{+}$ $\mu$ mol were then given until the $\mathrm{FEV}_{1}$ fell by $10-19 \%$ when the test continued with doubling increments. For subjects with a history $\frac{}{\mathbb{D}}$ suggestive of asthma the starting dose was $\frac{a}{\sigma}$ $0.048 \mu \mathrm{mol}$ and doubling increments were used throughout. The test ended when the $\mathrm{FEV}_{1}$ had fallen by $20 \%$ or more, or a cumulative dose of $12 \cdot 25 \mu \mathrm{mol}$ methacholine had been given.

\section{PEAK FLOW RECORDINGS}

On arrival subjects completed the questionnaire and skin tests were performed. Subjects were then shown how to use a mini Wright 
Table 3 Relationship between PEF variability and skin weal diameter, age, sex, and smoking history. Regression coefficients for amplitude \% mean and absolute amplitude are for $\log _{10}$ transformed values; coefficients for mean PEF values are untransformed

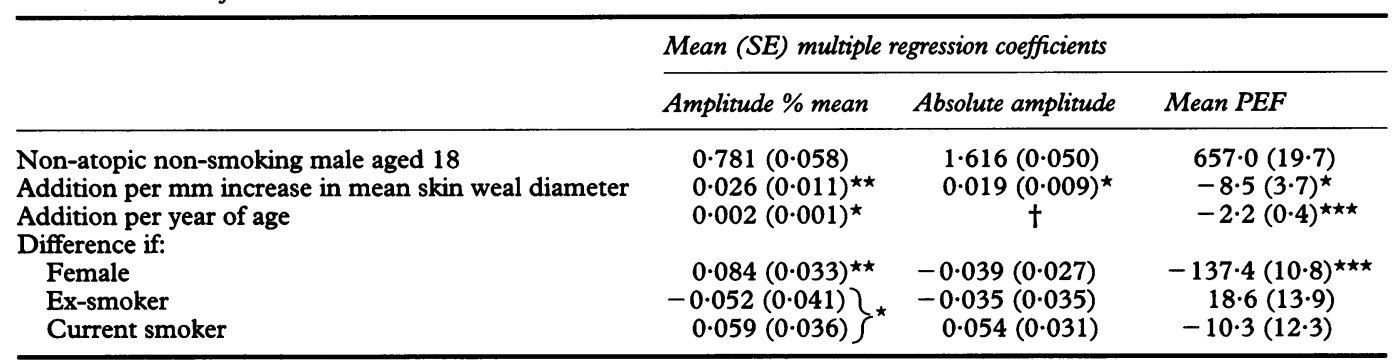

${ }^{\star} \mathrm{p}<0.05 ;{ }^{\star \star} \mathrm{p}<0.01 ;{ }^{\star \star \star} \mathrm{p}<0.001 ;$ tcoefficient negligible.

peak flow meter and how to fill in a purpose designed record sheet with spaces for recordings at two hourly intervals throughout the day, commencing at $02 \cdot 00$ hours. They were asked to record their PEF within 15 minutes of the times shown every day for a week during waking hours. It was emphasised that spaces should be left blank rather than insert inaccurate data if a measurement was missed.

Subjects were asked to return the meter and completed record sheet by post and were given a strong stamped addressed envelope for this purpose. If the meter was not returned by post subjects were visited at home.

\section{SKIN TESTS}

Skin prick tests were performed on the ventral aspect of the forearm using Dermatophagoides pteronnysinus, grass pollen, and cat dander as test reagents with histamine and saline as controls. Skin weal size was measured after 10 minutes as the mean of the largest diameter and that at right angles to it, excluding any pseudopodial outgrowths.

\section{ANALYSIS OF RESULTS}

The results of the challenge tests were analysed by a curve fitting method ${ }^{8}$ to determine the methacholine $\mathrm{PD}_{20}$. Extrapolation of the curve to one doubling dose above the maximum dose administered-that is, to 24.5 $\mu \mathrm{mol}$-was carried out if the $\mathrm{FEV}_{1}$ had not

Table 4 Effects of skin weal size, age, sex, and smoking history on the odds of having a $P D_{20}$ methacholine $<24.5 \mu$ mol. Coefficients are for $\log _{e}$ (odds). Significance levels based on difference in deviance compared with $\chi^{2}$ distribution. Age coefficients for current and ex-smokers are for difference compared with non-smokers

\begin{tabular}{|c|c|c|}
\hline Factor & Estimate (SE) & \\
\hline $\begin{array}{l}\text { Non-atopic non-smoking male } \\
\text { aged } 18\end{array}$ & $-3 \cdot 46(1 \cdot 68)$ & \\
\hline $\begin{array}{l}\text { Addition per } \mathrm{mm} \text { increase in mean } \\
\text { skin weal diameter }\end{array}$ & $1.48(0.52)^{\star \star}$ & \\
\hline $\begin{array}{l}\text { Difference if: } \\
\text { Female } \\
\text { Ex-smoker } \\
\text { Current smoker }\end{array}$ & 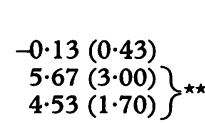 & \\
\hline $\begin{array}{l}\text { Addition with age (per year): } \\
\text { in ex-smokers } \\
\text { in current smokers }\end{array}$ & $\left.\begin{array}{r}0.06(0.03) \\
-0.15(0.08) \\
-0.08(0.04)\end{array}\right\}$ * & Smoking/age interaction \\
\hline $\begin{array}{l}\text { Interaction between age and skin weal } \\
\text { diameter }\end{array}$ & $-0.03(0.01)^{\star}$ & \\
\hline
\end{tabular}

${ }^{\star} \mathrm{p}<0.05 ;{ }^{\star \star} \mathrm{p}<0.01$. fallen by $20 \%$ after the maximum dose of methacholine.

Peak flow records were first scrutinised to detect possible falsification of results. The variability of $P E F$ in each subject was then determined as amplitude $\%$ mean $^{6}$ :

$$
\frac{\text { highest } \mathrm{PEF} \text { reading }- \text { lowest }}{\text { mean }} \times 100
$$

To calculate the response rates, subjects aged over 65 , those who had left the electoral district, and those who had died since the electoral register was compiled were excluded from analysis. Subjects who were ill or could not be traced were counted as non-responders. Numbers responding for each survey method were compared by the $\chi^{2}$ test.

Smoking history was determined from two questions, one asking if subjects had ever smoked on a daily basis for at least a year, and the second if they had smoked at all in the last month. Subjects answering both questions affirmatively were classified as current smokers, those answering both negatively as non-smokers, and those who had had no cigarettes in the last month but had smoked for a year or more in the past were classified as ex-smokers.

The mean skin weal diameter of each subject was calculated by subtracting the saline control value from each of the house dust, grass, and cat weal diameters, and taking the mean of these three values.

The relationship between amplitude \% mean and age, sex, mean skin weal diameter, and smoking history was determined by multiple linear regression with amplitude $\%$ mean as the dependent variable. Sex and smoking were entered as categorical factors using three levels of smoking representing current, exsmokers, and non-smokers. Identical analyses were performed with the two components of amplitude \% mean, amplitude and mean PEF as dependent variables. A similar analysis was performed for the results of bronchial challenge tests but in this case multiple logistic regression was used with reactor status as the categorical dependent variable, a reactor being defined as a subject with a $\mathrm{PD}_{20}$ value below $24.5 \mu \mathrm{mol}$. The interactions between age and both atopy and smoking were tested for significance. The effect of controlling for baseline $\mathrm{FEV}_{1}$ on the relationship between bronchial reactivity and 


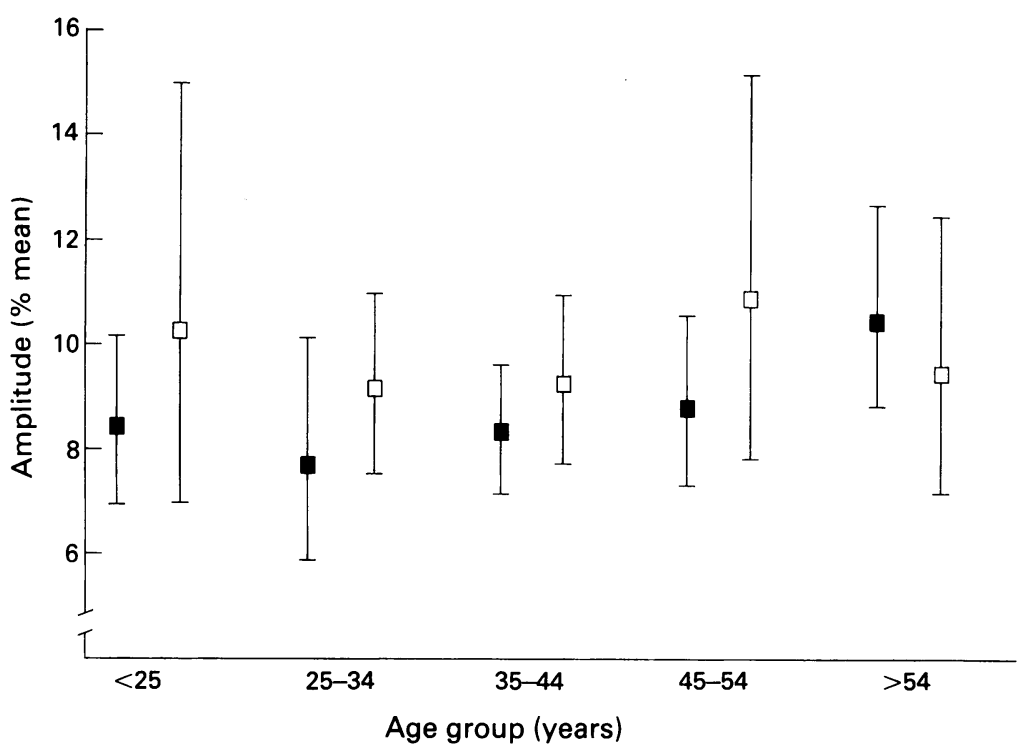

Figure 1 Mean (95\% confidence intervals) amplitude \% mean by mean skin weal size and age group. Atopic subjects ( $\square$ ) are those with one or more skin weals $\geqslant 2 \mathrm{~mm}$; nonatopic subjects (ם) are those with all skin weals $<2 \mathrm{~mm}$.

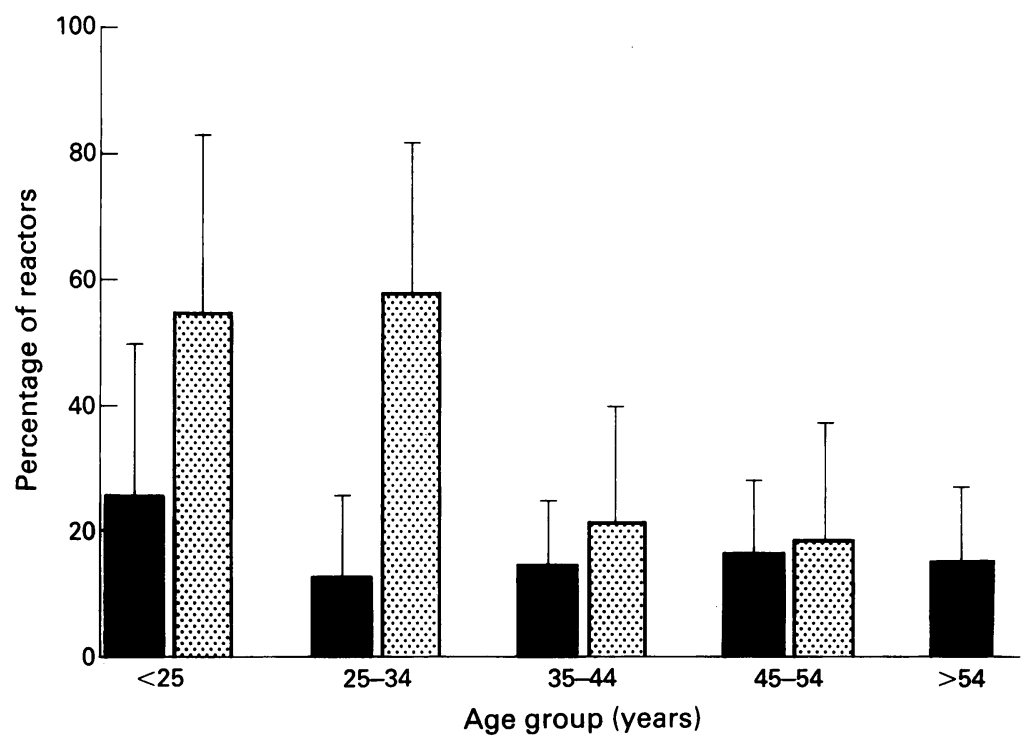

Figure 2 Percentage of reactors $\left(\mathrm{PD}_{20}<24.5 \mu \mathrm{mol}\right)$ with $95 \%$ confidence limits by age and atopic status. Atopic subjects (圖) are those with one or more skin weals $\geqslant 2 \mathrm{~mm}$; non-atopic subjects ( ) are those with all skin weals $<2 \mathrm{~mm}$. The atopic subject group $>54$ years is not shown since it contains only three subjects.

smoking was determined. $\log _{10}$ transformed values of amplitude $\%$ mean and $\mathrm{PD}_{20}$ were used throughout. The regression analyses were performed using the statistical program GLIM.

\section{Results}

\section{RESPONSE RATES}

After exclusion of subjects aged over 65 and those who had moved outside the area or died since the electoral register was constructed, 377 subjects were eligible for a bronchial challenge test and 394 for measurement of PEF variability. A total of 212 subjects $(56 \cdot 2 \%)$ attended for challenge tests, and 273 subjects $(69 \cdot 3 \%)$ accepted a PEF meter (table 1). However, 26 subjects failed to return an adequate $\mathrm{PEF}$ record so that only $247(62 \cdot 3 \%)$ could be analysed. Challenge tests could not be performed in 10 cases because of low $\mathrm{FEV}_{1}(n=8)$ or poor spirometric technique $(n=2)$ leaving 202 $(53.6 \%)$ completed tests. The difference 국 between response rates $(62.3 \% v 53.6 \%)$ is significant (difference $=8 \cdot 7 \%$; 95\% confi-? dence interval $=8 \cdot 1 \% ; \mathrm{p}<0.05)$.

Incomplete questionnaires, skin test $\stackrel{\text { ? }}{\frac{7}{0}}$ refusal, or unsatisfactory skin tests excluded $\frac{\bar{O}}{\underline{\sigma}}$ data from a further 29 subjects from the $\frac{\overline{\bar{\rho}}}{}$ full regression analysis for PEF variability $\mathbb{\otimes}$ and 31 subjects from the full analysis of bronchial reactivity. The age, sex, and smok- $\overrightarrow{0}$ ing characteristics of the subjects included in the analysis are given with their atopic status $\vec{\omega}$ in table 2.

COMPLETENESS OF PEF DATA

For each available two hourly time point a total of 1729 PEF readings was possible- 0 that is, seven days in each of 247 subjects. At 0 all times from 08.00 to 22.00 hours inclusive the number of measurements recorded was $\omega$ between $72 \%$ and $80 \%$ of the possible total. $\frac{\mathbb{O}}{0}$ The percentage fell to $21 \%$ at 06.00 and $15 \% \frac{\mathbb{D}}{3}$ at midnight. Few measurements were made at 02.00 or 04.00 hours.

RELATIONSHIP OF PEF VARIABILITY TO AGE, SEX, ATOPY, AND SMOKING HISTORY

Amplitude \% mean was higher in women than in men $(9.7 \% v 8.5 \%, p<0.05)$ and this was the only factor which had a signifi-

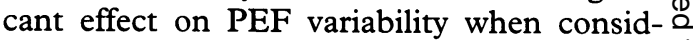
ered alone. In multiple regression analysis, $\overrightarrow{\overrightarrow{0}}$ after controlling for sex, amplitude \% mean showed a significant increase with increasing age, was lower in ex-smokers and higher in current smokers than in non-smokers, and $\vec{\sigma}$ increased with increasing mean skin weal diameter (table 3 ). There was no interaction between age and smoking nor between age and atopy (fig 1).

The differences in amplitude \% mean seen with smoking and atopy were produced by 을 changes in both absolute amplitude and mean $\rightarrow$ PEF. Absolute amplitude increased with skin weal diameter and was higher in current $\bar{N}$ smokers: mean PEF showed the converse changes (table 3 ). In contrast, both absolute $N$ amplitude and mean PEF were lower in $\mathrm{\omega}$ women and mean PEF decreased with age; the changes in mean PEF with age and sex were greater than those in absolute amplitude, accounting for the increase in ampli- 0 tude $\%$ mean with age and female sex.

RELATIONSHIP OF BRONCHIAL REACTIVITY TO AGE, SEX, ATOPY, AND SMOKING HISTORY A total of 45 subjects $(22 \cdot 3 \%)$ had a $\mathrm{PD}_{20}$ methacholine $<24.5 \mu \mathrm{mol}$. The odds were significantly greater in current smokers and with increasing skin weal diameter (table 4). Allowance for baseline $\mathrm{FEV}_{1}$ made little difference to the effect of smoking. Age and sex did not significantly alter the odds of having a $\mathrm{PD}_{20}$ below $24.5 \mu \mathrm{mol}$. There was, however, a significant interaction between age and atopy (as defined by their product) with a 


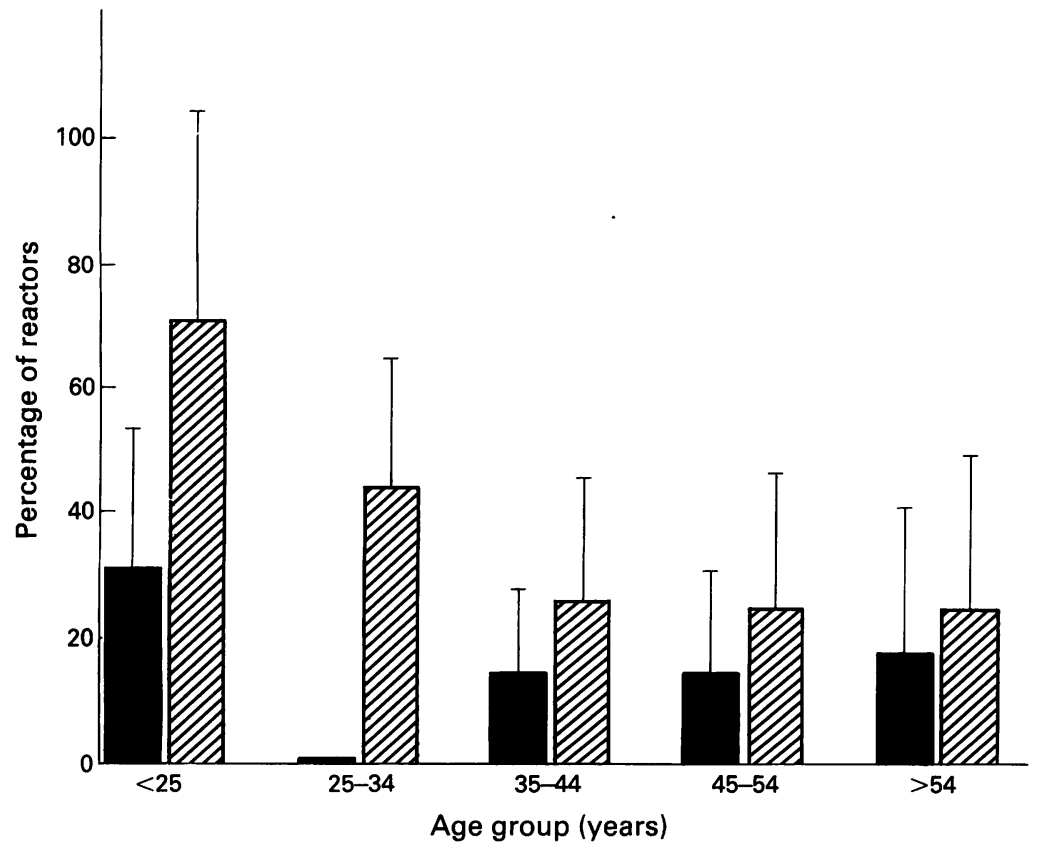

Figure 3 Percentage of reactors $\left(P D_{20}<24.5 \mu \mathrm{mol}\right)$, with $95 \%$ confidence limits, by age

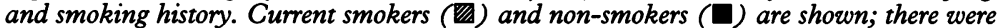
few ex-smokers in the younger age groups and they are omitted.

decline in the effects of atopy with increasing age (table 4, fig 2), and between smoking and age, the increased reactivity in current smokers being less pronounced with age (table 4, fig 3).

\section{Discussion}

The associations of bronchial reactivity with smoking and atopy have been reported previously, but this is the first time that the relations of these factors to PEF variability have been studied in randomly selected subjects. Although bronchial reactivity and PEF variability are both measures of airway lability, they are obtained in different ways and are likely to reflect different aspects of airway behaviour. The results from this study in randomly selected subjects, however, show that both measurements vary with factors known to be associated with airways disease. The strength of the associations of the two measurements with these factors cannot be compared since the measurements were not made in identical subject groups.

Amplitude \% mean was positively associated with mean skin weal diameter, the increase with increasing weal diameter being produced by complementary changes in absolute amplitude (increase) and mean PEF (decrease). The difference is present in all age groups except those aged $>54$ years (fig 2). Atopic status is one of the major risk factors for the development of asthma and any proposed measure of airway lability would be expected to show a relationship to atopy. Such an association might also be expected on the basis of the changes which occur when allergen challenge is carried out under controlled laboratory conditions ${ }^{9-11}$ : airway calibre falls as an immediate response to allergen challenge followed several hours later by an increase in bronchial reactivity. Natural exposure of atopic asthmatic subjects to allergen would thus be expected to lower PEF readings directly and to increase the susceptibility to bronchoconstrict when exposed to other stimuli, leading to increased PEF variability.

The odds of having a methacholine $\mathrm{PD}_{20}$ below $24.5 \mu \mathrm{mol}$ also increased as skin weal diameter increased. Several previous surveys have shown a relationship between atopic status and bronchial hyperreactivity. ${ }^{12-17}$ Seasonal variation in bronchial reactivity has been found in wheat workers ${ }^{18}$ and in a community population selected because of occasional wheeze, ${ }^{19}$ and these changes are assumed to be related to seasonal changes in allergen levels. In the laboratory allergen challenge can produce an increase in bronchial reactivity ${ }^{9-11}$ and the airway response to allergen can be predicted from a prior knowledge of the histamine $\mathrm{PD}_{20}{ }^{20-23}$ We also found, as in a previous study, ${ }^{13}$ an interaction between age and atopy with a significant reduction in the proportion of atopic subjects with measurable $\mathrm{PD}_{20}$ values with increasing age.

Current smokers had higher levels of amplitude \% mean than non-smokers or exsmokers. The difference between smoking categories was slightly more pronounced in the younger age groups but this trend was not statistically significant. The increased values in young current smokers suggest that the effect of cigarettes on the airways can occur after relatively short exposure. As with atopy the changes in amplitude \% mean with smoking history were contributed to by an increase in the absolute amplitude and a decrease in mean PEF.

Most studies which have considered the effects of cigarette smoking on bronchial reactivity in community samples have shown, as in the present study, an increased proportion of smokers among subjects with a measurable $\mathrm{PD}_{20}$ value. ${ }^{132-28}$ In some such studies the effects of smoking have been seen mainly in subjects with low baseline airway calibre, ${ }^{2728}$ a finding consistent with the theory that long term smoking alters bronchial reactivity through an effect on airway calibre. There is also evidence of short term effects of smoking on airway calibre and bronchial reactivity, ${ }^{29}{ }^{30}$ and in our study the increased proportion of current smokers with a measurable $\mathrm{PD}_{20}$ was present, as with amplitude \% mean, in all age groups and was, in fact, more obvious in the younger age groups as shown in fig 3 . The figure may exaggerate the extent of the increase in the youngest age group which contained only seven smokers, but the results suggest that smoking can alter bronchial reactivity after relatively short exposure when changes in airway calibre would be expected to be minimal. The effect of smoking on bronchial reactivity remained after controlling for baseline $\mathrm{FEV}_{1}$, again favouring the suggestion that smoking may have a more direct influence on reactivity.

Previous reports which have considered the 
effects of age on bronchial reactivity have generally, like the present study, been based on cross sectional surveys. Studies which have included both children and adults have shown a fall in the proportion of reactors to methacholine and cold air with increasing age, ${ }^{3132}$ the lowest levels being seen in subjects in their forties. In adults there appears to be an increase in the number of reactors as age increases above $40-50$ years, ${ }^{33-36}$ although one recent study has shown the opposite. ${ }^{37}$ In combination these results tend to suggest a U-shaped distribution with reactivity greatest in early and late adult life. In contrast to $\mathrm{PD}_{20}$, amplitude \% mean showed a small steady increase with age (fig 2). This appears to be due principally to the well recognised decline in mean PEF with age, since absolute amplitude was relatively constant across the age range studied. Although the age related variation in amplitude \% mean was significant it was not large, the expected value for amplitude \% mean in a non-smoking nonatopic man changing from $6.6 \%$ at age 20 to $8.5 \%$ at age 60 .

There was no difference in $\mathbf{P D}_{20}$ values between men and women, and no consistent association with sex has been reported in adults. ${ }^{1537}$ Both mean PEF and absolute amplitude were lower in women than in men, but the difference was proportionately larger for mean PEF so that amplitude \% mean was significantly greater in women. In our sample more women than men had a history of asthma $(9 \cdot 7 \%$ v $6 \cdot 1 \%)$ which may account for some of the difference in PEF variability between the sexes, but amplitude \% mean was also higher in women in the subjects who reported no asthma. In practice the sex difference could be allowed for in studies using amplitude \% mean measurements as is currently done for other indices of lung function such as $\mathrm{FEV}_{1}$.

One of the main reasons for performing this study was to compare response rates for the two survey methods. In terms of the number of people attending for a challenge test or to collect a PEF meter there was a distinctly better response with PEF recordings. Some subjects failed to return their PEF record, however, and some were unable to complete challenge tests, so that the final difference was $8 \cdot 7 \%$. Of the 26 subjects who accepted a PEF meter but failed to return a completed record 23 claimed to have posted it, and it is difficult to disbelieve them all. Some packages were returned in a damaged state and it is possible that some were lost in the postal system. Even allowing for these losses PEF recordings were associated with a higher response rate than challenge tests and this is likely to be the case in future studies, at least when conducted in adults in countries with high literacy rates.

In addition to the difference in response rates the use of PEF recordings was much simpler logistically than challenge tests, although this is difficult to quantify formally. PEF meters can be distributed more quickly than challenge tests can be performed, even by experienced personnel. Appointment systems for PEF recordings are easier to organise and several subjects can be instructed together. If subjects need to be visited at home it is much easier to deliver a PEF meter and give instructions than to perform a challenge test, and the PEF method can be used by non-medically trained personnel.

There are limitations to PEF measurements. Some researchers may not feel comfortable with the lack of supervision the method entails. The need to correct for age and sex adds a minor complication. Perhaps most important is the finding from a previous study, in subjects selected because of a history of wheeze, that subjects who had been given a diagnosis of asthma were separated more clearly from non-asthmatic subjects by use of bronchial reactivity than by PEF variability measurements. ${ }^{38}$ However, there was little difference between the measurements when the relationships to respiratory symptoms were compared.

In summary, we have confirmed in a random population sample that bronchial reactivity measurements are associated with atopy and smoking, and have shown that these factors are also related to increased PEF variability. The effects of atopy and smoking on bronchial reactivity show interactions with age which we did not find for PEF variability but, despite this difference, our findings suggest that measurement of PEF variability is a suitable alternative to bronchial challenge tests for epidemiological studies. In particu- $\mathbb{\Phi}$ lar, it may be more suitable for studies involv- $\overrightarrow{\vec{F}}$ ing repeated measurements in which its $\frac{0}{3}$ greater acceptability and absence of censored data would be important. A measure of PEF variability can be obtained in all subjects in a population sample who accept a peak flow meter; it appears to produce a higher response rate than bronchial challenge tests and is associated with factors known to be related to airways disease.

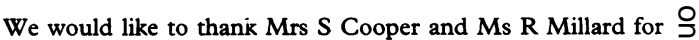
assistance with bronchial challenge testing and the distribution of PEF meters; Dr S Walsh and Mrs Y Himsworth of $\frac{7}{O}$ South Lincolnshire Health Authority for help in setting up the study; the many general practitioners in South Kesteven who $\mathrm{N}$ supported the work; and the British Lung Foundation for $\sigma$ financial support (grant 86/18). Miss S Chinn and Mr KW Lai were funded by the Department of Health.

1 Britton J, Tattersfield AE. Does measurement of bronchial hyperreactivity help in the clinical diagnosis of $\mathbb{D}$ asthma? Eur 7 Respir Dis 1986;68:233-8.

2 Sears MR, Jones DJ, Holdaway MA, Hewitt CJ, Flannery 7 EM, Herbison GP, et al. Prevalence of bronchial reac- $\bar{D}$ tivity to inhaled methacholine in New Zealand school- $\frac{O}{\mathbb{D}}$ children. Thorax 1986;41:283-9.

3 Adelroth E, Hargreave FE, Ramsdale EH. Do physicians need objective measurements to diagnose asthma? $A m$ 으 Rev Respir Dis 1986;134:704-7.

4 Salome CM, Peat JK, Britton WJ, Woolcock AJ. Bronchial hyperresponsiveness in two populations of $\frac{O}{0}$ Australian schoolchildren. 1. Relations to respiratory symptoms and diagnosed asthma. Clin Allergy 1987;17: 271-81

5 Pattemore PK, Asher MI, Harrison AC, Mitchell EA, Rea ? $\mathrm{HH}$, Stewart A. Ethnic differences in prevalence of

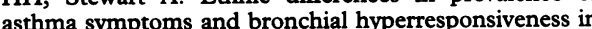
New Zealand schoolchildren. Thorax 1989;44:168-76.

Higgins BG, Britton JR, Chinn S, Jones T, Jenkinson D, Burney PGJ, et al. The distribution of peak expiratory flow variability in a population sample. Am Rev Respir Dis 1989;140:1368-72. 
7 Yan K, Salome C, Woolcock AJ. Rapid method for measurement of bronchial responsiveness. Thorax 1983; 38:760-5.

8 Chinn S, Britton JR, Burney PGJ, Tattersfield AE, Papacosta AO. Estimation and repeatability of the response to inhaled histamine in a community survey. Thorax 1987;42:45-52.

9 Cockcroft DW, Ruffin RE, Dolovich J, Hargreave FE. Allergen-induced increase in non-allergic bronchial reactivity. Clin Allergy 1977;7:503-13.

10 Cartier A, Thomson NE, Frith PA, Roberts R, Hargreave FE. Allergen-induced increase in bronchial hyperresponsiveness to histamine: relationship to the late asthmatic response and change in airway calibre. $f$ Allergy Clin Immunol 1982;70:170-7.

11 Durham SR, Craddock CF, Cookson WO, Benson MK. Increases in airway responsiveness to histamine precede allergen-induced late asthmatic response. I Allergy Clin Immunol 1988;82:764-70.

12 Cockcroft DW, Murdock KY, Berscheid BA. Relationship between atopy and bronchial responsiveness to histamine in a random population. Ann Allergy 1984;53: 26-9.

13 Burney PGJ, Britton JR, Chinn S, Tattersfield AE, Papacosta AO, Kelsen MC, et al. Descriptive epidemiology of bronchial reactivity in an adult population: results from a community survey. Thorax 1987;42: results

14 Peat JK, Britton WJ, Salome CM, Woolcock AJ. Bronchial hyperresponsiveness in two populations of Australian schoolchildren. II. Relative importance of associated factors. Clin Allergy 1987;17:283-90.

15 Trigg CJ, Bennett JB, Tooley M, Sibbald B, De Souza MF, Davies RJ. A general practice based survey of bronchial hyperresponsiveness and its relation to symptoms, sex, age, atopy and smoking. Thorax 1990;45: 866-72.

16 Peat JK, Woolcock AJ. Sensitivity to common allergens: relation to respiratory symptoms and bronchial hyperresponsiveness in children from three different climatic areas of Australia. Clin Exp Allergy 1991;21:573-81.

17 Clough JB, Williams JD, Holgate ST. Effect of atopy on the natural history symptoms, peak expiratory flow, and bronchial responsiveness in 7 and 8-year-old children with cough and wheeze. A 12 month longitudinal study. Am Rev Respir Dis 1991;143:755-60.

18 Hensley MJ, Scicchitano R, Saunders NA, Cripps AW, Ruhno J, Sutherland D, et al. Seasonal variation in nonspecific bronchial reactivity: a study in wheat workers with a history of wheat associated asthma. Thorax 1988, 42:103-7.

19 Britton J, Chinn S, Burney P, Papacosta AO, Tattersfield AE. Seasonal variation in bronchial reactivity in a community population. I Allergy Clin Immunol 1988;82: 134-9.

20 Kreukniet J, Pijper MM. Response to inhaled histamine and to inhaled allergen in atopic subjects. Respiration 1973;30:345-59.

21 Killian D, Cockcroft DW, Hargreave FE, Dolovich J. Factors in allergen induced asthma: relevance of the intensity of the airways allergic reaction and nonspecific bronchial reactivity. Clin Allergy 1976;6:219-25.

22 Bryant DH, Burns MW. Bronchial histamine reactivity: its relationship to the reactivity of the bronchi to allergens. Clin Allergy 1976;6:523-32.
23 Cockcroft DW, Murdock KY, Kirby J, Hargreave FE. Prediction of airway responsiveness to allergen from skin sensitivity to allergen and airway responsivness to histamine. Am Rev Respir Dis 1987;135:264-7.

24 Welty C, Weiss ST, Tager IB, Munoz A, Becker C, Speizer FE, et al. The relationship of airways responsiveness to cold air, cigarette smoking, and atopy to respiratory symptoms and pulmonary function in adults. Am Rev Respir Dis 1984;130:198-203.

25 Taylor RG, Joyce H, Gross E, Holland F, Pride NP. Bronchial reactivity to inhaled histamine and annual rate of decline in $\mathrm{FEV}_{1}$ in male smokers and exsmokers. Thorax 1985;40:9-16.

26 Woolcock AJ, Peat JK, Salome CM, Yan K, Anderson $\mathrm{SD}$, Schoeffel RE, et al. Prevalence of bronchial responsiveness and asthma in a rural adult population. Thorax 1987;42:361-8.

27 Rijcken B, Schouten JP, Weiss ST, Speizer FE, Van der Lende $R$. The relationship between airway responsiveness to histamine and pulmonary function level in a random population sample. Am Rev Respir Dis 1988; 137:826-32.

28 Lim TK, Taylor RG, Watson A, Joyce H, Pride NP. Changes in bronchial responsiveness to inhaled histamine over four years in middle-aged male smokers and ex-smokers. Thorax 1988;43:599-604.

29 Gerrard J, Cockcroft D, Mink J, Cotton D, Poonwala R, Dosman J. Increased non-specific bronchial reactivity in cigarette smokers with normal lung function. Am Rev Respir Dis 1980;122:577-81.

30 Cerveri I, Bruschi C, Zoia MC, Maccarini L, Grassi M, Lebowitz MD, et al. Smoking habit and bronchial reactivity in normal subjects: a population based study. $A m$ Rev Respir Dis 1989;140:191-6.

31 Weiss ST, Tager IB, Weiss JW, Munoz A, Speizer FE, Ingram RH. Airway responsiveness in a population sample of adults and children. Am Rev Respir Dis 1984; 129:898-902.

32 Townley RG, Bewtra A, Wilson AF, Hopp RJ, Elstein $\mathrm{RC}$, Nair $\mathrm{N}$, et al. Segregation analysis of bronchial response to methacholine inhalation challenge in families with and without asthma. I Allergy Clin Immunol 1986;77:101-7.

33 Alanko K. Prevalence of asthma in a Finnish rural population. Scand $\mathcal{F}$ Respir Dis 1970;76(Suppl):1-64.

34 Van der Lende R, Visser BF, Wever-Hesse J, De Vries $K$, Orie NGM. Distribution of histamine threshold values in a random population. Rev Inst Hyg Mines 1973;28: 186-90.

35 Lang DM, Hopp RJ, Bewtra AK, Nair NM, Watt GD, Townley RG. Distribution of methacholine inhalation challenge responses in a selected adult population. f Allergy Clin Immunol 1987;79:533-40.

36 Rijcken B, Schouten JP, Weiss ST, Speizer FE, Van der Lende $R$. The relationship of non-specific bronchial responsiveness to respiratory symptoms in a random population sample. Am Rev Respir Dis 1987; 136:62-8.

37 Bakke PS, Baste V, Gulsvik A. Bronchial responsiveness in a Norwegian community. Am Rev Respir Dis 1991; 143:317-22.

38 Higgins BG, Britton JR, Chinn S, Jones TE, Burney PGJ, Tattersfield AE. A comparison of bronchial reactivity and peak expiratory flow variability measurements for epidemiological studies. Am Rev Respir Dis 1992;145: 588-93. 